\title{
Characterization on the Properties of Jute Fiber at Different Portions
}

\author{
Sweety Shahinur, ${ }^{1,2}$ Mahbub Hasan, ${ }^{2}$ Qumrul Ahsan, ${ }^{3}$ \\ Dilip Kumar Saha, ${ }^{4}$ and Md. Saiful Islam ${ }^{5}$ \\ ${ }^{1}$ Bangladesh Jute Research Institute, Manik Mia Avenue, Dhaka 1207, Bangladesh \\ ${ }^{2}$ Department of Materials and Metallurgical Engineering, Bangladesh University of Engineering Technology, Dhaka 1000, Bangladesh \\ ${ }^{3}$ Department of Engineering Materials, Faculty of Manufacturing Engineering, Universiti Teknikal Malaysia, 76100 Melaka, Malaysia \\ ${ }^{4}$ Bangladesh Atomic Energy Commission, Dhaka 1000, Bangladesh \\ ${ }^{5}$ Department of Chemistry, Faculty of Science, Universiti Putra Malaysia, 43400 Serdang, Selangor, Malaysia
}

Correspondence should be addressed to Mahbub Hasan; mahbubmmebuet@gmail.com

Received 2 December 2014; Revised 10 January 2015; Accepted 27 March 2015

Academic Editor: Vitor Sencadas

Copyright (c) 2015 Sweety Shahinur et al. This is an open access article distributed under the Creative Commons Attribution License, which permits unrestricted use, distribution, and reproduction in any medium, provided the original work is properly cited.

\begin{abstract}
Natural fibers are environment-friendly, biodegradable, nonabrasive, and less costly and exhibit high initial modulus and high moisture absorption. However, they have nonuniformity in their mechanical, physical, chemical, and thermal properties at different portions. For this reason, long jute fiber was cut into three different portions and subsequently characterized using single fiber tensile test, differential scanning calorimetric, thermogravimetric analysis, X-ray diffraction, and scanning electron microscopy according to top, middle, and cutting portions. The crystallinity and moisture content were measured by XRD data and moisture absorption test of the different portions of the raw jute fiber, respectively. The middle portion had better mechanical, thermal, chemical, and crystalline properties compared to the other two portions of the jute fiber. The diameter gradually became thinner from cutting to top portions. Thus the middle portion of jute fiber would be the better choice while being used as reinforcement in composites.
\end{abstract}

\section{Introduction}

A broad variety of natural fibers are nowadays available that can be used as filler in green composites due to their better physicochemical and physicomechanical properties. In recent times the natural fibers have found new field of application as reinforcement in composites for replacing the man-made synthetic fibers such as carbon [1]. Environmental regulations brought paradigm shift in the composite market. Thus, the interest of the natural fiber reinforced polymer composite in the composite market and in engineering application has increased significantly $[1,2]$.

Natural fibers such as hemp, coir, bamboo, palm, and kenaf are easily available, inexpensive, light, renewable, biodegradable, and environmentally acceptable. Jute is a biodegradable, cheap, nontoxic, environment-friendly, and longest bast fiber. Due to the advent of cheap synthetic substitutes, bulk handling, containerization, and storage in soils, jute and jute goods are losing market sharply in the countries. Diversified use of jute is therefore essential in order to prevent further decline of the jute sectors [2]. However, the physicomechanical properties of the jute fiber vary in a wide range. For this reason, jute fibers are not used in the large range in the diversified production sectors. In order to diversify the use of jute fiber, various chemical treatments were conducted on jute fiber. In some places, jute was mixed with other materials [3-8]. Uddin et al. blended top, middle, and bottom portion of jute with jute cotton and found significant variation in properties. The top and cutting portions had comparable results when blended with jute cotton $[3,4]$. Shahinur reported that the tensile properties of different portions of the jute fiber became similar after chemical treatment. However the properties were different in three different portions in raw jute fiber [5]. Wang et al. prepared micro and no fibrils from jute fiber using chemical treatment and reported better properties in the jute fibrils [6]. Teli and 
Valia conducted acetylation on jute to improve oil absorbency [7]. However, raw jute fiber was not characterized properly and the thermal properties were not evaluated according to different portions. The chief weakness of natural fibers is that they have different properties in different portions due to different maturity of the cell in different portions. The deviation of the properties also varies in wide range as natural fiber contains a wide range of nonhomogeneity $[9,10]$. As a result, jute composites prepared using different portion of the jute fiber will not show uniform properties. In order to investigate the properties of different portions of jute fiber, long jute fiber was cut into three portions (top, middle, and cutting) in the present research. Those portions were subsequently characterized using physical, mechanical, and thermal techniques.

\section{Methodology}

Jute fiber was collected from Bangladesh Jute Research Institute, Bangladesh. The origin of the fiber was Faridpur region situated at middle part of Bangladesh. The collected fibers were cut manually into three portions (top, middle, and cutting) of approximately $250 \mathrm{~mm}$ in length (Figure 1). The single fiber was characterized by tensile testing using 6353 Instron machine (Instron, USA) at the crosshead speed $5 \mathrm{~mm} / \mathrm{sec}$ [10]. The fiber span length was $5 \mathrm{~mm}, 15 \mathrm{~mm}$, $25 \mathrm{~mm}$, and $35 \mathrm{~mm}$. The span length effect was corrected by newly developed method [10]. The moisture content was measured by conventional method at room temperature, moisture, and rainy conditions. The surface morphology of the fiber was observed under a scanning electron microscope. The moisture absorption characteristics of the different portions were studied at distilled water, $10 \% \mathrm{HCl}$, and $10 \%$ $\mathrm{NaCl}$ using ASTM-D 570. Fiber crystallinity was measured by X-ray diffraction data. A Norelco type 120-101-85 Philips electronic diffractometer with nickel filtered copper $\mathrm{K} \alpha$ was used. X-ray diffraction data were collected from the equatorial diffraction profiles using 5 to 15 steps scanning $(2 \theta)$, method of "top of smoothed peak," fiber diagram. Thermal properties were measured using a thermogravimetric analyzer (TA Instruments SDT Q50) on 8-10 mg raw jute fiber at a heating rate of $5^{\circ} \mathrm{C} / \mathrm{min}$ in a nitrogen atmosphere. Differential scanning calorimetric analysis was also carried out to measure thermal properties using a DSC Q10 (TA Instruments) thermal system with a sealed aluminum capsule. $10 \mathrm{mg}$ jute fiber was used and the temperature was varied in between 0 and $500^{\circ} \mathrm{C}$.

\section{Results and Discussion}

3.1. Surface Morphology. The whole jute fiber was cut into three portions as top, middle, and cutting/bottom (Figure 1). The surface morphology of the top, middle, and cutting portions was found different according to their thickness that was due to variation of the jute fiber maturity. The top fiber was immature, middle fiber was properly matured, and cutting portion was overmatured [11] (Figure 2). There were less pores and voids on the top portion fiber surface

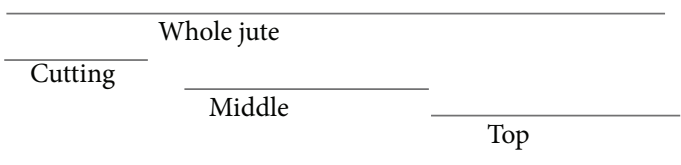

FIGURE 1: Cutting process of whole jute fiber.

as compared to the surfaces of middle and cutting portions. Physically top portion was branched in soft and light colour. Middle portion was beautiful in colour and glassy, while cutting portion was rough and dark in colour as compared to the top and middle portion [12]. The top portion had less diameter $(40 \mu \mathrm{m})$ due to immaturity, while the middle and cutting portion had sufficient diameter due to their cellulose content [13]. The diameter of the middle and cutting portions was approximately $65 \mu \mathrm{m}$ and $75 \mu \mathrm{m}$, respectively.

3.2. Tensile Properties. The tensile strength, Young's modulus, and strain to failure of middle portion jute fiber were higher as compared to the top and cutting portions (Figure 3). This was due to the higher cellulose content of the middle portion [13]. One important thing is that middle portion fibers were matured, whereas the top and cutting portions were immature and overmature, respectively [11]. The tensile strength and strain to failure for all portions decreased with span length. This is because the lower test span length was much affected by fiber properties and machine parameters. On the other hand, Young's modulus increased with span length as found in previous research $[10,11]$.

3.3. Moisture Content Results. The moisture content of raw jute fiber of different portions is shown in Figure 4. The middle portion of jute fiber showed exceptional results compared to the top and cutting portions due to its high cellulose and free hydroxyl (-OH) group content [13]. At room and moisture condition middle portion had lower moisture content than the other two portions; as a result mechanical and thermal properties of middle portion were higher compared to top and cutting portions [14].

3.4. Crystallinity Analysis. The XRD pattern, as well as crystallinity of the top middle and cutting portions, was similar (Figure 5). The crystallinity of the top portion of jute fiber was slightly higher as compared to the middle and cutting portions, which could be due to the presence of less dense fats and waxes or lignin in the top portion [15]. As a result there were less pores and voids on the top portion fiber surface. From the XRD data, it can be clearly seen that the width at half-height of the 002 at $29-18^{\circ}$ and $29-24^{\circ}$ was similar to top, middle, and cutting portions of the fibers. There was only a small difference in the positions of these peaks [16].

\subsection{Thermal Properties}

3.5.1. Thermogravimetric Analysis. The thermal properties of different portion of jute are shown in Figure 6 and tabulated in Table 1 . The thermograph of individually three-portion 


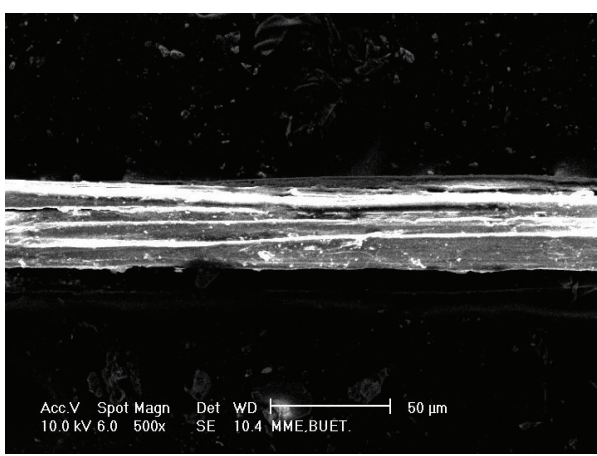

(a)

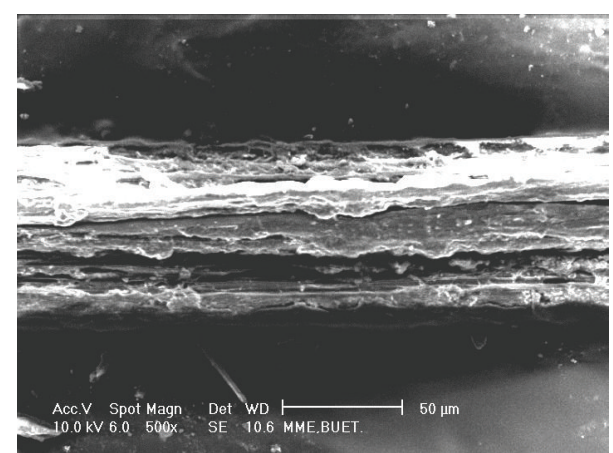

(b)

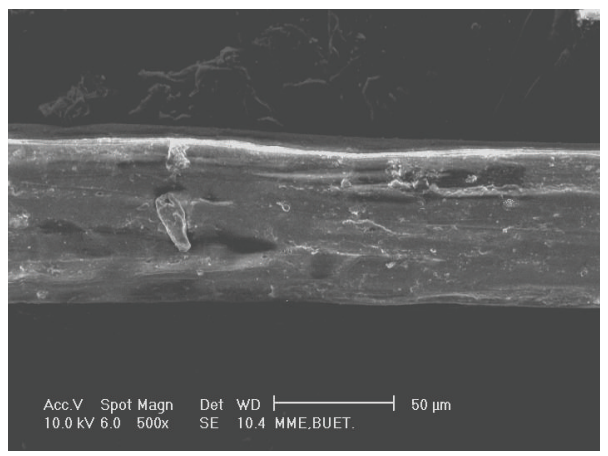

(c)

FIGURE 2: Surface morphology of (a) top, (b) middle, and (c) cutting portions of raw jute fiber.

TABLE 1: Thermal properties of different portions of jute fiber.

\begin{tabular}{|c|c|c|c|}
\hline \multirow[b]{2}{*}{ Portion } & \multicolumn{3}{|c|}{ Degradation temperature $\left({ }^{\circ} \mathrm{C}\right)$ of } \\
\hline & Moisture & $\begin{array}{l}\text { Cellulose and } \\
\text { hemicellulose }\end{array}$ & Lignin \\
\hline Top & 100 & 290 & 325 \\
\hline Middle & 101 & 280 & 310 \\
\hline Cutting & 100 & 285 & 320 \\
\hline
\end{tabular}

jute fiber presented three stages (from 25 to $180^{\circ} \mathrm{C}$, from 180 to $280^{\circ} \mathrm{C}$, and from 280 to $500^{\circ} \mathrm{C}$ ) of decomposition [17]. The middle portion of raw jute fiber had higher derivative change (Figure 6(a)) due to higher cellulose [13] content as compared to the top and cutting portion during increase in temperature. The thermal stability was similar to different portions but the weight change of the fiber rapidly changed in case of middle portion, followed by cutting and top portions, respectively. This was related to the moisture content of the different portions of jute fiber [5]. The first 10\% weight loss (Figure 6(b)) occurred due to moisture evaporation and $20-30 \%$ weight loss occurred due to degradation of light materials such as hemicellulose and cellulose, while $70 \%$ weight loss occurred due to decomposition of heavy material like lignin of the jute fiber $[17,18]$. The degradation temperature of cellulose was higher than the hemicellulose $\left(25-290^{\circ} \mathrm{C}\right)$ and lignin $\left(150-420^{\circ} \mathrm{C}\right)$. This was due to the fact that most of the cellulose structure was crystalline, which is strong and resistant to hydrolysis $[19,20]$. After the removal of the free water, the degradation process began in the cellulose, hemicelluloses, lignin constituents, and the associated linked water $[17,21]$.

DTGA curve showed a lower temperature peak at around $250^{\circ} \mathrm{C}$ for top portion fiber, which was due to the decomposition of hemicellulose. For the middle and cutting portion this peak was not visible, indicating the removal of hemicellulose from the fiber. Furthermore, a large peak at a temperature around $320^{\circ} \mathrm{C}$ was due to cellulose and lignin decomposition. At this stage, middle portion showed higher decomposition temperature compared to top and cutting portion of the jute fiber. This again proves that hemicellulose and lignin were less in the middle portion [17].

3.5.2. DSC Analysis. DSC curves of three portions of jute fibers are shown in Figure 7. Ball et al. reported that the endothermal reaction occurred due to volatilization (gases) of the molecules, whereas exothermal reaction occurred due to the formation of charring (solid residue) [18, 22]. The cutting portion shows a higher endothermic peak (around $100^{\circ} \mathrm{C}$ ) for water evaporation compared to the top and middle portion (around $80^{\circ} \mathrm{C}$ ). This result indicates that cutting portion has low hemicelluloses compared to middle and top. A small exothermic peak appeared at the temperature range of $250-290^{\circ} \mathrm{C}$ for cutting portion. This peak mainly occurred due to decomposition of hemicelluloses and a portion of lignin degradation. This exothermic peak disappeared from the top and middle portion of the jute fibers indicating greater amount of hemicellulose and lignin missing from the respected jute portions. 


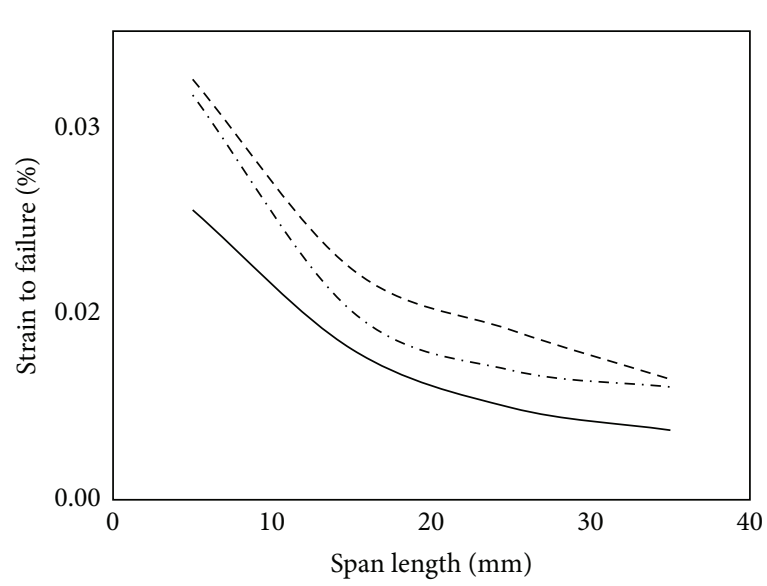

(a)

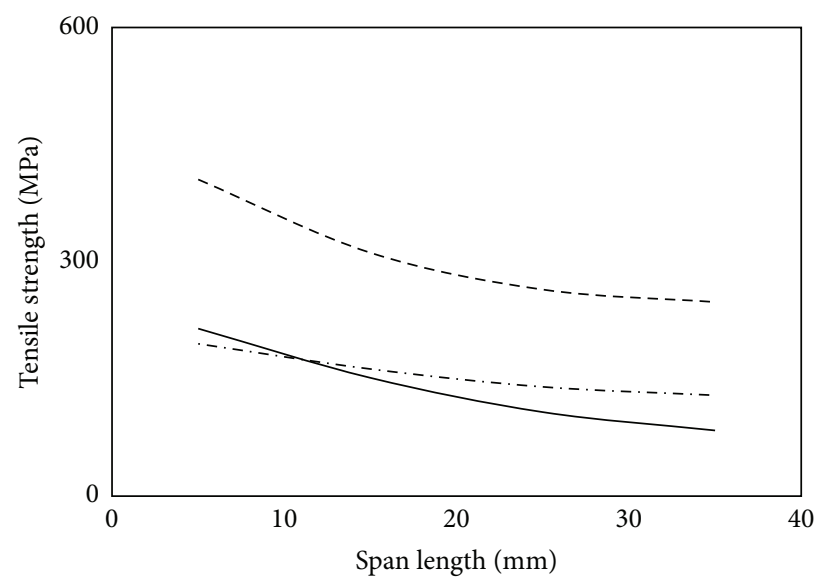

(b)

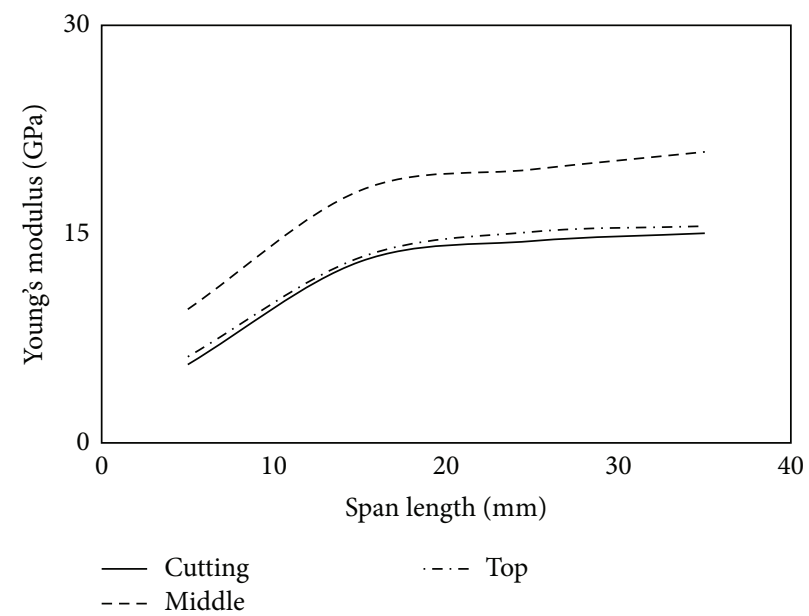

(c)

FIgURE 3: (a) Strain to failure, (b) tensile strength, and (c) Young's modulus of different portions of raw jute fiber.

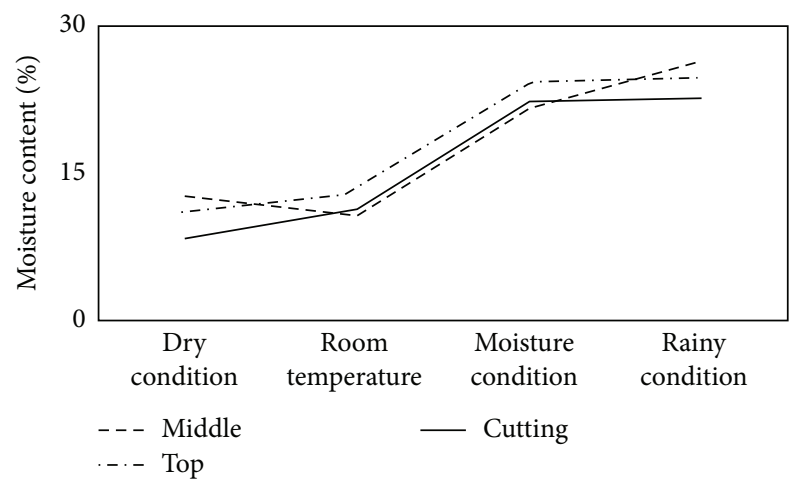

FIGURE 4: Moisture content of different portions of raw jute fiber.

\section{Conclusions}

The present study investigated the physical, mechanical, and thermal properties of different portion jute fiber. Single fiber tensile test, differential scanning calorimetric analysis,

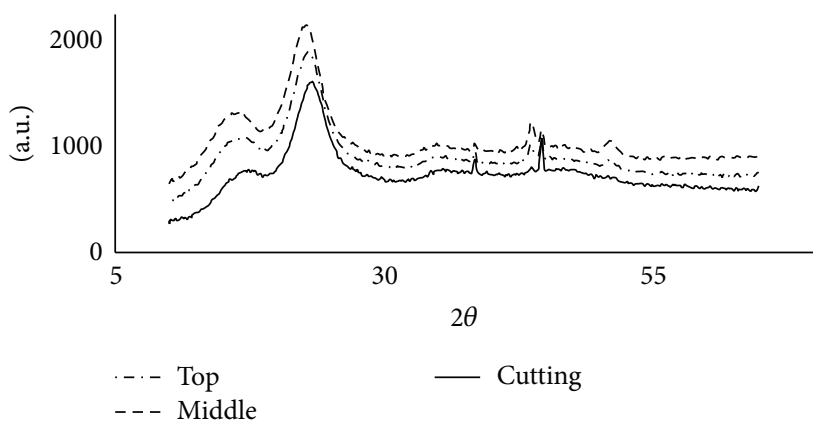

FIGURE 5: XRD pattern of the different portion of the raw jute fiber.

thermogravimetric analysis, X-ray diffraction analysis, and scanning electron microscopy on top, bottom, and cutting portions of jute fiber were carried out. The middle portion had higher tensile strength, strain to failure, and Young's modulus as compared to top and cutting portions. The surface of the cutting portion was rougher as compared to the 


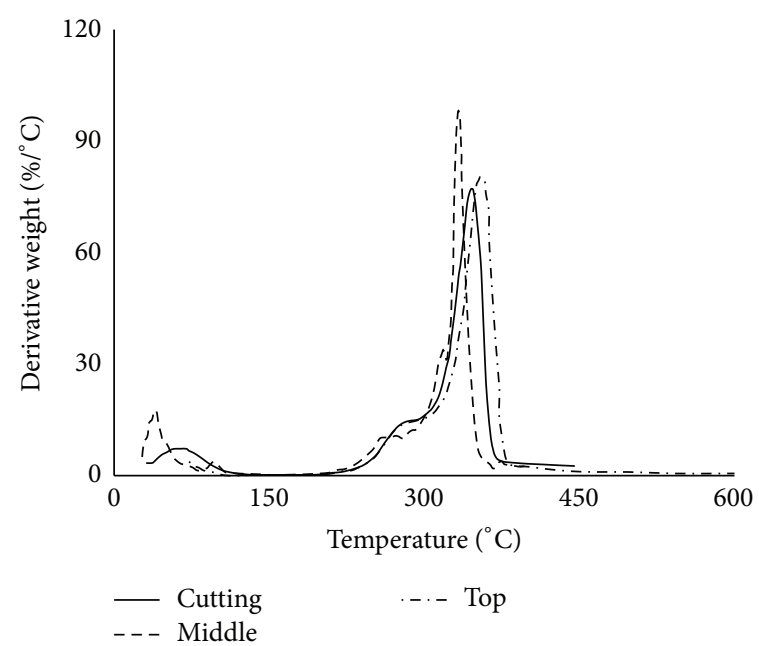

(a)

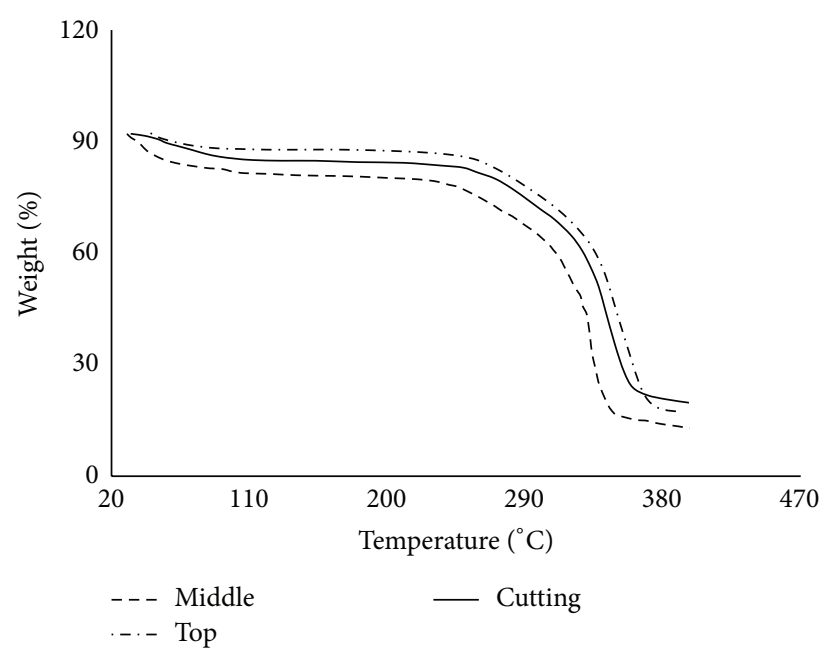

(b)

Figure 6: (a) DTGA and (b) TGA curves of different portions of raw jute fiber.

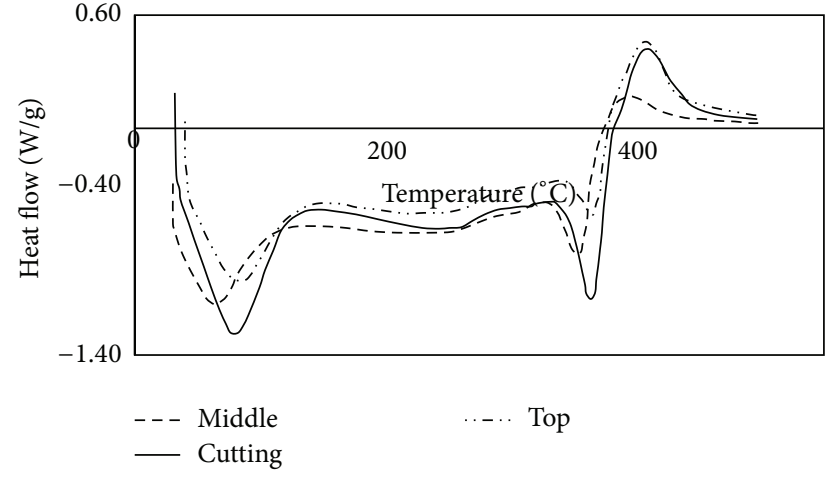

FIGURE 7: DSC curves of three portions of raw jute fibers.

top and middle portions. On the other hand, the crystallinity of different portions of jute fiber was similar. However, there was a small difference in the position of the peaks. The middle portion of jute fiber also had higher thermal stability as compared to the other two portions. Thus the middle portion should be used as reinforcement in composites.

\section{Conflict of Interests}

The authors declare that there is no conflict of interests regarding the publication of this paper.

\section{References}

[1] F. M. Al-Oqla and S. M. Sapuan, "Natural fiber reinforced polymer composites in industrial applications: feasibility of date palm fibers for sustainable automotive industry," Journal of Cleaner Production, vol. 66, pp. 347-354, 2014.

[2] H. M. Z. Hossain, Md. M. Kabir, N. Sultana, and S. Shahinur, "Potentiality of jute in pulp and paper industry of Bangladesh," Newsletter of BJRI, vol. 37, pp. 5-7, 2010.
[3] M. M. Uddin, M. A. M. Molla, S. Shahinur, N. Matin, M. K. Uddin, and H. A. Begum, Annual Report of Technological Research, BJRI, Dhaka, Bangladesh, 2005-2007.

[4] M. M. Uddin, M. S. Ullah, M. Asaduzzaman, M. A. M. Molla, and M. A. Kaysar, "Effect of blend ratio and different portions of jute on the physical properties of jute cotton blended ring spun yarn," International Journal of Sustain Agriculture Technology, vol. 5, pp. 64-70, 2009.

[5] S. Shahinur, Characterization of chemically modified jute fiber for polymer composite [M.Phil thesis], Department of Materials and Metallurgical Engineering, Bangladesh University of Engineering and Technology, Dhaka, Bangladesh, 2012.

[6] H. Wang, L. Huang, and Y. Lu, "Preparation and characterization of micro- and nano-fibrils from jute," Fibers and Polymers, vol. 10, no. 4, pp. 442-445, 2009.

[7] M. D. Teli and S. P. Valia, "Acetylation of Jute fiber to improve oil absorbency," Fibers and Polymers, vol. 14, no. 6, pp. 915-919, 2013.

[8] P. Saha, S. Manna, D. Roy et al., "Effect of photodegradation of lignocellulosic fibers transesterified with vegetable oil," Fibers and Polymers, vol. 15, no. 11, pp. 2345-2354, 2014.

[9] A. K. Bledzki and J. Gassan, "Composites reinforced with cellulose based fibres," Progress in Polymer Science, vol. 24, no. 2, pp. 221-274, 1999.

[10] S. Biswas, Q. Ahsan, I. Verpoest, and M. Hasan, "Effect of span length on the tensile properties of natural fibers," Advanced Materials Research, vol. 264-265, pp. 445-450, 2011.

[11] S. Shahinur, M. Hasan, and Q. Ahsan, "Outcome of rot retardant treatment on the mechanical properties of different portions jute fiber," Bangladesh Journal of Physics, vol. 13, pp. 59-64, 2013.

[12] Md. S. Ullah, Md. M. Uddin, N. Matin et al., Annual Report of Technological Research, BJRI, Dhaka, Bangladesh, 2008-2009.

[13] M. M. Hossen and M. Begum, Annual Report of Technological Research, BJRI, Dhaka, Bangladesh, 2005-2007.

[14] A. Hassan, N. A. Rahman, and R. Yahya, "Moisture absorption effect on thermal, dynamic mechanical and mechanical properties of injection-molded short glass-fiber/polyamide 6,6 composites," Fibers and Polymers, vol. 13, no. 7, pp. 899-906, 2012. 
[15] A. K. Varma, S. R. A. Krishnan, and S. Krishnamoorthy, "Effect of chemical treatment on density and crystallinity of Jute fibers," Textile Research Journal, vol. 59, no. 6, pp. 368-370, 1989.

[16] S. K. Kundu, "Flexural bending fatigue of raw and chemically treated jute," Textile Research Journal, vol. 57, no. 2, pp. 118-120, 1987.

[17] M. M. Kabir, Effects of chemical treatment on hemp fiber reinforced polyester composites [Ph.D. thesis], University of Southern Queensland, Toowoomba, Australia, 2012.

[18] A. Fardausy, M. A. Kabir, H. Kabir et al., "Study of physical, mechanical and thermal properties of unidirectional jute fiber reinforced PVC film composites," International Journal on Advanced Research in Engineering and Technology, vol. 3, no. 2, pp. 267-274, 2012.

[19] V. Placet, "Characterization of the thermo-mechanical behaviour of Hemp fibres intended for the manufacturing of high performance composites," Composites Part A: Applied Science and Manufacturing, vol. 40, no. 8, pp. 1111-1118, 2009.

[20] B. Tajeddin, R. A. Rahman, L. C. Abdulah, N. A. Ibrahim, and Y. A. Yusof, "Thermal properties of low density polyethylenefilled kenaf cellulose composites," European Journal of Scientific Research, vol. 32, no. 2, pp. 223-230, 2009.

[21] H. J. Kim and Y. G. Eom, "Thermogravimetric analysis of rice husk flour for a new raw material of lignocellulosic fiberthermoplastic polymer composites," Journal of the Korean Wood Science and Technology, vol. 29, no. 3, pp. 59-67, 2001.

[22] R. Ball, A. McIntosh, and J. Boindley, "Feedback processes in cellulose thermal decomposition: implications for fire-retarding strategies and treatments," Combustion Theory and Modeling, vol. 8, pp. 59-67, 2004. 

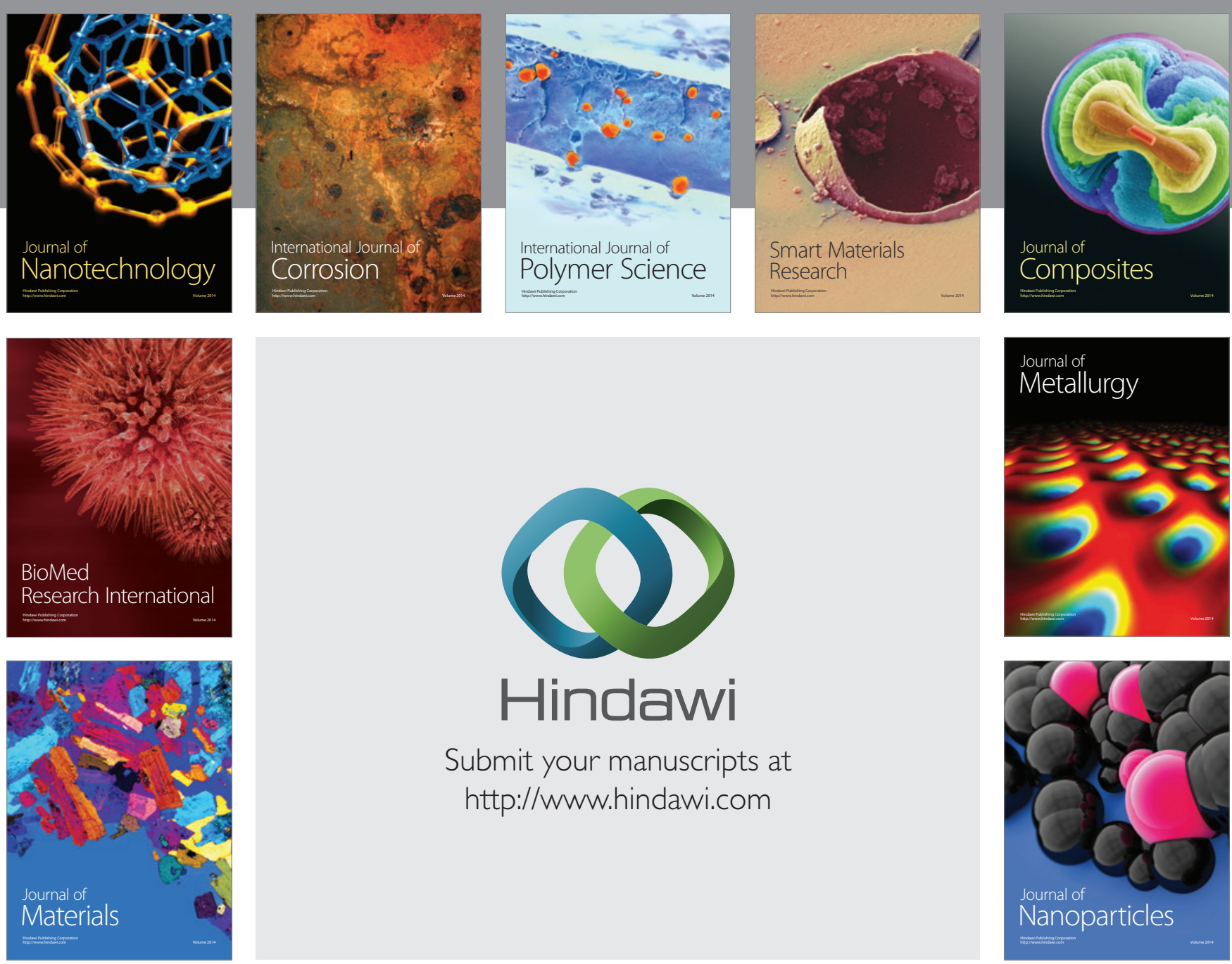

Submit your manuscripts at http://www.hindawi.com
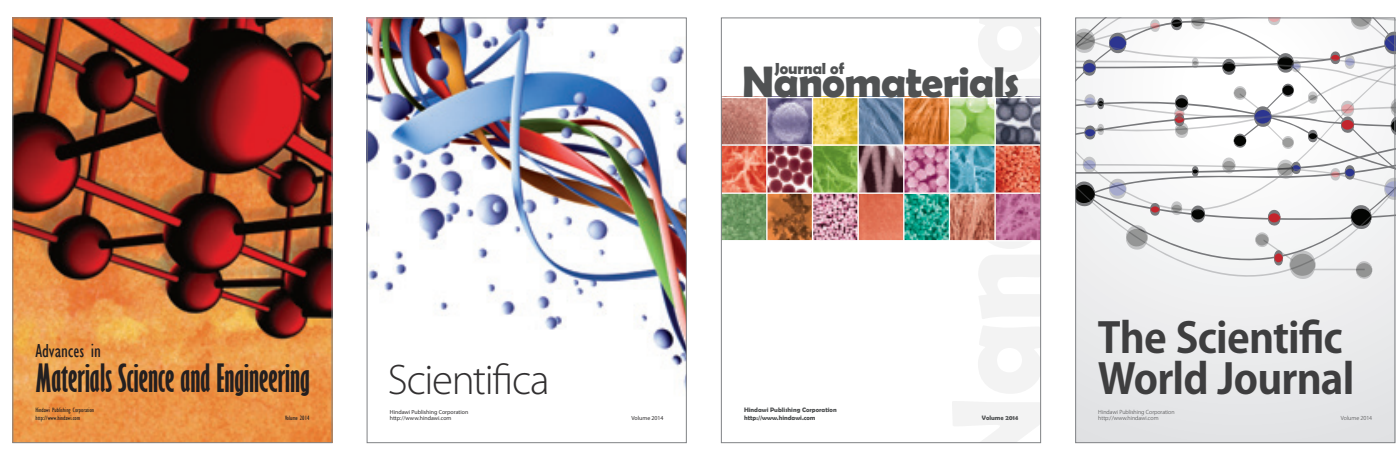

\section{The Scientific World Journal}
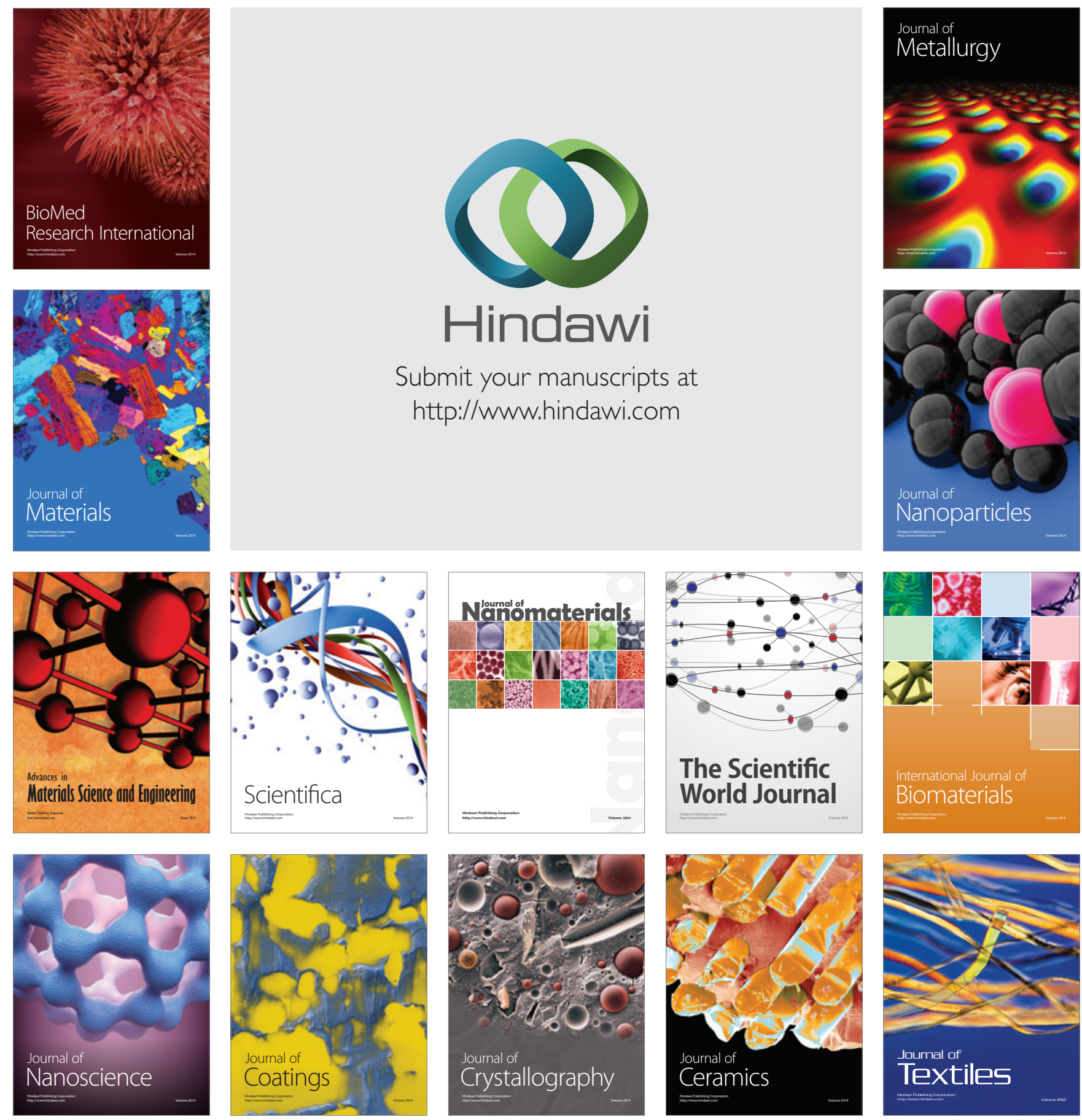